\title{
Entrevista com Stephen J. Ball Privatizações da educação e novas subjetividades: contornos e desdobramentos das políticas (pós) neoliberais
}

SanNy SILVA DA ROSA *

Data: 2 de abril de 2012

\section{APRESENTAÇÃO}

Stephen J. Ball ${ }^{1}$ é autor que já dispensa apresentações aos pesquisadores e estudiosos brasileiros do campo das políticas educacionais. Seus estudos, pesquisas e publicações, desde a década de 1980, investigam as origens, os desdobramentos e os efeitos das reformas educacionais produzidas no contexto mais geral das reformas do Estado orientadas pelo espírito frenético de mudanças da "economia do conhecimento" (Knowledge Economy). O fato de debruçar-se, mais particularmente, sobre as reformas e mudanças do sistema de ensino no Reino Unido não impede que as contribuições de seu trabalho atinjam um público amplo. Isto porque, de acordo com o próprio autor, "a educação inglesa tem cumprido especial papel no desenvolvimento e disseminação de um 'discurso global de educação', como um laboratório social de experimentação e de reformas” (Ball, 2008, p. 1). Nos últimos cinco anos, Ball tem se dedicado intensivamente ao estudo das novas formas e modalidades de privatização da oferta e gerenciamento dos serviços públicos da educação não apenas na Inglaterra, mas também em outros países e regiões do mundo, inclusive do mundo oriental.

* Doutora em educação (Currículo) e integrante da linha de pesquisa Políticas Públicas e Reformas Educacionais e Curriculares do programa de pós-graduação em educação Currículo - da Pontifícia Universidade Católica de São Paulo (PUC-SP); pesquisadora visitante do Instituto de Educação da Universidade de Londres, UK.E-mail: ssdarosa@ uol.com.br.

1 Stephen J. Ball é professor do Instituto de Educação da Universidade de Londres, onde é "Karl Mannheim Professor" da Faculdade de Política e Sociedade. 
Em 2007, publicou o livro Education Plc, título que, em português, pode ser traduzido por Educação Ltda. Neste trabalho, o autor apresenta os resultados de uma ampla pesquisa sobre os processos de privatização do setor educacional público na Inglaterra, nas duas últimas décadas, em decorrência das reformas promovidas inicialmente pelo governo conservador de Margareth Thatcher, levado adiante pelo Novo Trabalhismo de Tony Blair e atualmente pelo governo de coalizão de conservadores e liberais democratas. Em 2008, o autor publicou o livro The Education Debate [O debate da Educação], obra que discute e analisa as origens históricas e os efeitos de três "tecnologias políticas" utilizadas nas reformas educacionais inglesas orientadas pela "economia do conhecimento" (Knowledge Economy): a forma de mercado, o gerencialismo e a performatividade. Em 2012, foram lançados mais dois trabalhos: Global Education Inc.: New Policy Networks and neo-Liberal Imaginary, cujo argumento central é o de que novas instituições filantrópicas, empresários e governos vêm se unindo para formar novas redes e espaços para a produção de políticas exteriores ao Estado; e How Schools Do Policy: Policy Enactments in Secondary Schools, este em coautoria com Meg Maguire e Annete Braun, ${ }^{3}$ obra na qual os autores apresentam e discutem resultados de pesquisas realizadas entre 2010-2012 em escolas públicas consideradas “ordinárias": escolas comuns, dentro e fora de Londres, com desempenho dentro da "média nacional". O principal objeto destes estudos de caso - que consistiram em entrevistas com diferentes atores (professores, gestores, funcionários), análise de documentos e de outros artefatos escolares (espaços físicos, materiais tecnológicos, impressos, iconográficos, entre outros) - refere-se ao que Ball denominou de policy enactments ou "encenação das políticas", conceito que se opõe ao de "implementação", visto que colocar as políticas "em cena" implica o envolvimento e o trabalho das subjetividades nos processos de leitura, interpretação e tradução das políticas em práticas concretas e institucionalmente situadas. Nesse movimento abre-se uma distância ( $g a p$ ) entre os textos legais e as ações cotidianas nas quais operam as subjetividades atravessadas pelo discurso oficial.

Como nos trabalhos anteriores, nestes últimos o autor também se vale do método da sociologia política e, em particular, da análise do discurso para aproximar-se dessa problemática. Outra característica comum desses trabalhos é a análise descritiva de inúmeros exemplos e casos ilustrativos retirados da imprensa diária, de depoimentos de diferentes sujeitos, de documentos oficiais, de material publicitário, entre outros. Estes são recursos valiosos para que o leitor estrangeiro se familiarize com a realidade estudada por este autor que se diz preocupado com os destinos e contornos assumidos pela educação contemporânea. Esta entrevista - concedida em abril de 2012 - teve como foco a inter-relação dos temas discutidos nesses

2 A resenha deste livro foi publicada por Sanny Silva da Rosa na Revista Brasileira de Educação, v. 17, n. 49, p. 227-230, jan.-abr. 2012.

3 Meg Maguire é professora de sociologia da educação do departamento de educação e estudos profissionais do King's College London, UK. Annete Braun é docente de sociologia da educação do departamento de sociologia da City University, London, UK. 
trabalhos: ou seja, os efeitos da intensificação das privatizações do setor público sobre as subjetividades dos sujeitos-atores na "encenação" das políticas. Uma breve sinopse de cada uma das obras mencionadas foi colocada no final da entrevista para melhor situar o leitor sobre o seu conteúdo.

S.S.R. - Eu gostaria de iniciar esta entrevista falando de seu livro Education Plc (2007) que, pelo fato de não ter sido traduzido para o português, permanece pouco conhecido dos pesquisadores brasileiros. Nesse trabalho você apresenta uma visão abrangente, mas também bastante detalhada, do processo de privatização do setor educacional ocorrido na Inglaterra nas últimas décadas. Como você mesmo afirmou, este assunto ainda é pouco compreendido e pouco estudado. Além do seu, que outros estudos nesta mesma linha de investigação já foram desenvolvidos e como você os relaciona com o seu trabalho atual?

S.J.B. - Provavelmente um trabalho que mantém grande similaridade com Education Plc é o livro de Patricia Burch, de 2009, chamado Hidden Markets: The New Education Privatization [Mercados ocultos: a nova privatização da educação], no qual a pesquisadora norte-americana analisa a participação de fornecedores privados na educação, especificamente no programa No Child Left Behind ${ }^{4}$ nos Estados Unidos. O que ela faz neste estudo é semelhante ao que eu tentei fazer em Education Plc em sentido amplo. Isto é, eu procurei mapear esta participação, mapear o envolvimento dos fornecedores privados no setor educacional no Reino Unido. $\mathrm{E}$ isto porque ainda temos uma compreensão muito pequena sobre a abrangência, sobre a complexidade e a profundidade dessas formas de participação que envolvem o setor privado na oferta de serviços públicos e, particularmente, de serviços educacionais em países como o Reino Unido, Estados Unidos da América, em outras partes da Europa, na Nova Zelândia, Austrália, e mesmo em Hong Kong, Japão e em muitos outros lugares.

S.S.R. - Como essa "cartografia", então, se articula com a intenção teórica dessa linha de pesquisa que começou com Education Plc e agora é objeto de seu novo livro: Global Education Inc.?

S.J.B. - A ideia inicial do estudo, como eu disse, foi mapear esta participação, mas em relação tanto à compreensão do quanto ela faz parte de uma nova forma de "governança", e também parte do movimento de mudança da noção de hierarquia

4 O programa No Child Left Bebind (NCLB), instituído em 2001 por meio de ato do governo norte-americano de George W. Bush, fundamentou-se na premissa de que a fixação de altos padrões de desempenho e de metas mensuráveis obteriam melhores resultados especialmente entre alunos com desvantagem social. A lei exigiu que os estados desenvolvessem avaliações das competências básicas de todos os alunos a fim de obter verbas do governo federal. Escolas que repetidamente obtivessem baixos resultados estariam sujeitas a fechar ou passarem a ser administradas por empresas privadas. 
para a de heterarquia, da noção de burocracia para a de redes (networks) e que comumente diferem, dependendo da natureza, das formas e modalidades de Estado. Em Education Plc eu tentei avançar nesse tipo de análise, tanto no sentido de colocá-la numa perspectiva global, isto é, olhando particularmente para a participação de empresas ocidentais - mas também de companhias indianas e japonesas entre outras em todo o mundo - na oferta de serviços públicos, e procurei analisar como este processo vem contribuindo para a convergência de políticas educacionais responsáveis pelo que nós poderíamos chamar hoje de "políticas educacionais globais". $\mathrm{O}$ que eu tento entender é a emergência, em termos globais, desses novos espaços e formas de governança que existem acima, além e entre nações e estados. Este é o tema do livro mais recente, Global Education Inc.

S.S.R. - Em Education Plc (2007) e também em Global Education Inc. você marca bem a posição de que gostaria de "evitar uma condenação retórica" que possa levar a conclusões apressadas acerca desse movimento crescente e global de privatização dos serviços educacionais. Como esta postura cautelosa convive com as críticas contundentes que você tem feito ao avanço das politicas neoliberais (e pós-neoliberais) no campo educacional? Fale-nos um pouco sobre esta forma de abordar um objeto de estudo tão polêmico e ainda pouco explorado.

S.J.B. - O que eu tentei desenvolver em Education Plc não foi uma resposta retórica ou uma crítica a todo este processo, sem antes tentar entender estas mudanças. E para fazer isso, é preciso "descosturar" (no sentido de desconstruir) esse movimento, com a finalidade de, primeiro, descrevê-lo para, em seguida, analisar o que está acontecendo. Por isso eu afirmei que eu não estava tentando assumir posições em relação a todas essas mudanças e desdobramentos. É claro que eu estou tentando fazer uma crítica. Mas uma crítica fundamentada, baseada antes de tudo num entendimento sofisticado do que está acontecendo. O que eu tenho sustentado é a posição de que no período dos últimos quinze anos, em especial, estamos assistindo a uma enorme expansão da participação do setor privado na educação pública e que isso faz parte, em grande medida, do que eu chamo de uma fase pós-neoliberal do relacionamento do Estado com o setor privado.

S.S.R. - No livro The Education Debate (2008) você analisou de forma bastante didática as diferenças e similaridades entre as politicas neoliberais dos conservadores e aquelas alinhadas com os principios da chamada "terceira via" de Anthony Giddens (2000). Até que ponto é possivel reconhecer descontinuidades entre esses dois momentos (ou movimentos) politicos e ideológicos? As nuances de tais mudanças não ficam ainda mais obscuras no contexto do atual governo de coalizão entre conservadores e liberais- democratas na Inglaterra?

S.J.B. - Tenho dito que os processos que envolveram a passagem do modelo de "estado de bem estar social" (welfare state) para as práticas neoliberais no Reino Unido 
foram certamente muito bem captados pelo governo do Novo Trabalhismo de Tony Blair e perseguidos, até certo ponto, por meio do que se chama de "terceira via". Está claro também que tais práticas estão sendo levadas adiante pelo atual governo, baseadas na ideia de que vivemos numa "grande sociedade", na importância das políticas de "oportunidade de escolha" e de "participação" de novos fornecedores e gestores de serviços públicos. De forma que nós temos assistido à ocorrência deste movimento em cada período de tempo, mas também de novas iniciativas que vão sendo construídas a partir do que foi feito no período anterior, todas com o objetivo de desestabilizar antigas estruturas do setor público típicas do welfare state. No entanto, o que vemos hoje não é um tipo de neoliberalismo livre e selvagem, em que o mercado é autorizado a seguir o seu curso em qualquer setor na busca de obter maiores lucros, como foi pensado por Mrs. Thatcher. Diferente disso, o Estado se transformou num "criador de mercados", num regulador e monitor das ações do setor privado, que são marcas deixadas pelos governos do Novo Trabalhismo de Blair. Em outras palavras, o Estado hoje faz o papel de "parteiro" (midwife), produzindo relaçóes de mercado dentro das quais o setor privado tem a possibilidade de desenvolver atividades lucrativas na execução e gestão dos serviços públicos. Com isso, a clássica antítese e antagonismo entre o Estado e o setor privado precisa ser compreendida de forma diferente no que diz respeito à criação de oportunidades para o setor privado e às mudanças das formas e modalidades do próprio Estado.

S.S.R. - Nesses quatro livros mais recentes, você descreve e analisa alguns tipos de escolas públicas e formas de gestão escolar inspiradas no modelo empresarial. Entre eles, as City Technology Colleges, criadas pelos conservadores na década de 1980, seguidas pelas Academies, idealizadas pelo Novo Trabalhismo, nos anos de 1990. Sabemos que desde 2011 o governo Cameron criou as chamadas Free Schools (escolas livres). A despeito das diferenças partidárias de seus propositores, parece haver uma linha comum entre essas iniciativas. Como você analisa esse processo?

S.J.B. - Dentro disso tudo, é possível identificar basicamente três tecnologias políticas sendo utilizadas, desde Thatcher: a primeira é a "forma de mercado", criando oportunidades para a "escolha" e para a "competição", seja no interior dos serviços públicos já estabelecidos ou introduzindo a concorrência de fornecedores privados de serviços públicos. Ao lado disso, vemos também a introdução de formas de gestão que, por meio do fortalecimento do poder de controle dos gestores, fazem as instituições funcionarem de modo eficaz e eficiente de acordo com o modelo das organizações empresariais, isto é, de maneira a incentivar o engajamento de todos nesse processo de competição. Estas duas tecnologias políticas são complementadas por uma terceira tecnologia, que eu chamei de "performatividade" que consiste no desenvolvimento de medidas, de indicadores baseados em "sinais de mercado", mas que funcionam também como meio de o Estado controlar e definir metas para o gerenciamento e monitoramento do setor público. Isto é, servem também como base para o estabelecimento de novos contratos que vão permitir que os serviços 
públicos sejam ofertados (ou não) por fornecedores privados. Estas são características das políticas herdadas do Novo Trabalhismo e que nós podemos reconhecer em medidas que estão sendo adotadas, desenvolvidas e levadas adiante pelo atual governo de coalizão no Reino Unido. Uma das últimas exarações dessa ideia de "criar novas autonomias", novas "liberdades" e novas "oportunidades de escolha" são as assim chamadas Free Schools. Este é um novo tipo de escola que autoriza novos fornecedores a participarem da oferta de serviços públicos, para competir com outros tipos de escolas, como as Academies do Novo Trabalhismo de Blair - que continuam a existir - e que, por sua vez, foram inspiradas nas City Technology Schools criadas no governo conservador de Margareth Thatcher. E, de novo, nós podemos ver esse fenômeno como um processo de mudanças que vêm acontecendo ao longo do tempo, mas que são na verdade "novas repetições" a partir de "novas" demandas. Quanto ao pano de fundo de tudo isto, como eu disse antes, é possível argumentar que este processo remonta ao ímpeto neoliberal inicial presente no Reino Unido encarnado pelo "thatcherismo", termo que designa a conversão de Margareth Thatcher à filosofia econômica de Hayek, por influência de Keith Joseph, um político, ideólogo e economista muito influente no governo conservador da época.

S.S.R. - Que relaçôes e nexos você estabelece entre os estudos sobre as privatizações e sobre as mudanças no papel do Estado e os resultados dos estudos de caso em escolas públicas secundárias apresentados no livro How Schools Do Policy (Ball et al., 2012)?

S.J.B. - A pesquisa que realizei para Education Plc foi muito focada na questão dessa nova forma de economia política. Foi uma tentativa de compreender o desenvolvimento de novas formas de relacionamentos sociais, mas também a emergência de novas formas de subjetividade. Os sujeitos neoliberais são empreendedores, criativos, solipsistas, individualistas e desenvolvem um tipo de subjetividade que o neoliberalismo necessita para sobreviver. Eu penso que é necessário compreender tais desdobramentos como um conjunto de mudanças econômicas concretas, mas também como um conjunto de mudanças no interior das subjetividades. Ou como se tem dito (Barnes et al., 2003), o neoliberalismo não é algo que está apenas "lá fora", na economia, mas também aqui dentro, em nossas cabeças. Foi o que tentei investigar, em colaboração com Meg Maguire e Annete Braun, na pesquisa sobre policy enactments (encenação das políticas) - e que resultou no livro How Schools Do Policy, publicado este ano. O que pode ser dito como balanço geral do estudo realizado em quatro escolas secundárias (localizadas dentro e fora de Londres) consideradas "ordinárias" - isto é, dentro da média nacional em termos de desempenho - é que o principal impacto dessas mudanças tem sido o de mudar o significado

5 Uma Free School é uma escola financiada pelos contribuintes, mas não controlada por uma autoridade local. O conceito é baseado em escolas semelhantes encontradas na Suécia e nos Estados Unidos, onde são conhecidas como "escolas charter", fundadas e administradas pela iniciativa privada. 
da educação, mudar o sentido do processo da educação, ou seja, o que significa ser educado, o que significa ser um professor. Parte considerável dessas mudanças são efeitos do processo de mercantilização da educação, da transformação da educação em uma mercadoria que pode ser vendida e comprada. E isto não se aplica apenas aos tradicionais "resultados" da educação, na forma de exames e qualificações que podem ser convertidos em posições de oportunidade ou desvantagem no mercado de trabalho, mas se aplica também às ideias subjacentes às políticas e aos serviços educacionais. Agora são as ideias que se converteram em mercadorias que podem ser compradas e vendidas, ou seja, são as próprias políticas que fazem parte de um "mercado global", visto que há muitas empresas interessadas em "vender" tais ideias no mercado global de políticas educacionais. Foi exatamente isso o que tentei demonstrar em Global Education Inc.

S.S.R. - Quando se conversa com professores de escolas públicas primárias e secundárias inglesas tem-se a percep̧̧ão de que as inúmeras mudanças curriculares que decorrem das constantes mudanças na educação são motivo de apreensão, desconforto e incertezas dos docentes. Esta percep̧̧ão é correta? Gostaria que você comentasse um pouco como essa "biperatividade" politica tem afetado o trabalho dos professores.

S.J.B. - Eu penso que no contexto dessas mudanças na natureza dos processos de educação e do sentido da educação, o papel, a posição, as oportunidades e também a sensibilidade profissional dos professores foram profundamente modificadas. $\mathrm{E}$ isso, de novo, ocorre no sentido subjetivo e no sentido econômico. Dentro dessa arena mercadológica, especialmente a que convida à participação do setor privado, sabe-se que os gastos com salários representam o custo principal dos "prestadores de serviços" de educação escolar. Daí que se for possível introduzir a "flexibilização salarial" daqueles que desempenham os papéis e as tarefas do ensino, então também cresce a oportunidade de lucros, por meio da oportunidade de reduzir os salários. É por isso que uma das coisas que nós temos visto em todo o mundo, sob variadas formas, é o desenvolvimento de políticas de "flexibilização salarial", políticas que operam contra os movimentos dos sindicatos, políticas que mudam as formas e rotas de acesso à educação. De variadas formas são criadas oportunidades para empregar professores na base de "contratos" ou, ainda, contratar professores com baixos níveis de qualificação, o que permite, então, aos prestadores de serviços privados reduzirem os custos dos salários dos professores e, portanto, construírem oportunidades de lucro. Mas o modo como isto tudo opera e afeta as escolas como instituições diz respeito tanto aos efeitos das políticas de educação em geral como ao modo como cada escola, individualmente, reage e responde, em cada caso, a essa chuva de políticas. E tais reações e respostas dependem, isto é, são mediadas pela "posição de mercado" que cada escola consegue ocupar, pelo "poder de mercado" que cada escola consegue reivindicar. De modo que a oportunidade de se esquivar (de algumas políticas) ou de resistir a elas, ou ainda, de ser criativo ou flexível está relacionada com a posição de mercado ocupada pelas escolas, tanto em termos de 
sua relação com o Estado, isto é, do seu grau de autonomia em relação ao poder público, como também na relação com os seus "clientes" no que diz respeito às políticas educacionais.

S.S.R. - Em The Education Debate (2008) você argumentava que as reformas na verdade acabam reforçando as desigualdades sociais. Alison Wolf, em 2002, já insistia no grande gap (distância) existente entre a retórica (das políticas) e a realidade da educação no Reino Unido. O jornal inglês The Guardian (Youth..., 2011; University..., 2011) vem alertando, em notícias recentes, para o grande número de desempregados entre os jovens e para a queda do número de candidatos ao ensino superior no Reino Unido. É certo pensar que as mudanças e reformas introduzidas desde a década de 1980 efetivamente têm servido para democratizar o acesso à educação e melhorar a vida das pessoas? O que já se sabe sobre isso?

S.J.B. - Frente a tudo o que foi dito antes, o que se pode argumentar é que muitos aspectos das atuais políticas educacionais, pelo menos no curto prazo, operam em favor dos interesses da classe média. A política de "escolha", por exemplo, promove enormes oportunidades para a classe média usar suas habilidades e recursos de maneira a aumentar ou manter privilégios em relação às oportunidades educacionais e sociais. Então, uma das coisas que estou tentando fazer por meio de meu trabalho de pesquisa é estabelecer ligações entre os conceitos de classe, políticas e oportunidades em contraste a um amplo "cenário" de mudanças econômicas, sociais e na natureza do Estado. Isto é algo que eu busco apreender ao longo do meu projeto de trabalho e em minhas pesquisas atuais. É algo de que venho tentando me aproximar para contribuir para o que eu chamo de um "conhecimento estratégico" sobre o tema. Mas isto requer muito mais trabalho. O que já temos não é ainda conclusivo, não é definitivo. É uma tentativa ainda em desenvolvimento, em colaboração, e simultaneamente às contribuições de muitos outros estudiosos e pesquisadores em todo o mundo. Diria que este é um projeto de longo prazo e, para tanto, nós precisamos ter uma clara estratégia que efetivamente nos ajude a apreender o mundo em que nos encontramos.

S.S.R. - Em nome dos leitores brasileiros, gostaria de agradecer a concessão desta entrevista.

\section{SINOPSE DAS OBRAS COMENTADAS NESTA ENTREVISTA (EM ORDEM CRONOLÓGICA DE PUBLICAÇÕES):}

\section{7 - Education Plc: Understanding Private Sector Participation in Public Sector} Education. Nesta obra o autor apresenta um relato abrangente, analítico e empírico sobre as privatizações do setor público educacional no Reino Unido, fruto de análise de documentos, websites e entrevistas realizadas com os "novos atores" da indústria dos serviços da educação. O livro questiona o tipo de futuro pretendido para a educação e o papel que as privatizações e o setor privado podem vir a desempenhar nesse futuro. 
2008 - The Education Debate. O livro trata das iniciativas políticas introduzidas nos últimos vinte anos, particularmente na Inglaterra, e analisa os processos de rupturas e continuidades das reformas do sistema público de ensino inglês numa perspectiva histórica e sociológica. Aborda, com detalhes, as políticas liberalizantes e privatistas levadas a termo pelos governos de Margareth Thatcher e de Tony Blair e como as reformas orientadas pela "economia do conhecimento" e defendidas pelos organismos internacionais (OCDE, FMI, Banco Mundial) têm transformado o sentido da educação.

\section{2 - Global Education Inc.: New Policy Networks and the neo-Liberal Imaginary. O} argumento central deste livro é que as políticas de educação estão sendo reformadas e retrabalhadas em escala global com base nos métodos e princípios do "imaginário neoliberal”. Empresas, entidades filantrópicas e governos estão reunidos em novas redes e espaços políticos fora do âmbito do Estado-nação. Nesse novo cenário, o autor alerta para a necessidade de desenvolver novas ferramentas e perspectivas metodológicas para apreender essa sociologia política mais cosmopolita. De acordo com o autor, o livro não é uma discussão teórica sobre o neoliberalismo, mas antes é sobre o seu "como": como é promovido, como opera e funciona nas práticas mundanas. Ele registra, mapeia e dá sentido aos aspectos mais importantes destas novas relações e dinâmicas políticas em âmbito global, penetrando em seus microespaços.

\section{2 - How Schools Do Policy: Policy Enactments in Secondary Schools. A proliferação} de políticas preocupadas com a elevação dos padrões de desempenho (standards) nos últimos vinte anos tem produzido um clima de constantes mudanças nas escolas. Muita atenção tem sido dada aos estudos que investigam como tais políticas são "implementadas", mas poucos se preocupam em compreender como as escolas realmente lidam com essas múltiplas demandas, muitas vezes contraditórias. Resultado de estudos de caso realizados em quatro escolas públicas secundárias (com desempenho médio), os autores analisam como as políticas são postas "em cena" (a partir do conceito de policy enactment), com foco nos contextos do trabalho político das escolas e nos educadores como sujeitos (submetidos) mas também como agentes (atores) das políticas educacionais.

\section{REFERÊNCIAS}

BALL, Stephen J. Education Plc: understanding private sector participation in public sector education. London: Routledge; New York: Taylor \& Francis Group, 2007. . The education debate. Bristol, UK: The Policy Press University of Bristol, 2008. . Global Education Inc.: new policy networks and the neo-liberal imaginary. London: Routledge; New York: Taylor \& Francis Group, 2012.

.; Maguire, Meg; Braun, Annete. How schools do policy: policy enactments in secondary schools. London: Routledge; New York: Taylor \& Francis Group, 2012. 
Barnes, Trevor; Peck, Jamie; Sheppard, Eric; Tickell, Adam. Reading economic geography. USA; UK; Australia: Blackwell Publishing, 2003.

Burch, Patricia. Hidden markets: the new education privatization. New York: Routledge; Taylor \& Francis Group, 2009.

Giddens, Anthony. The third way and its critics. Cambridge, UK: Polity Press; Malden, USA: Blackwell Publishers, 2000.

Youth unemployment hits 1 million. The Guardian, Londres, UK, 16 nov. 2011. Disponível em: <http://www.guardian.co.uk/business/2011/nov/16/youthunemployment-hits-1m-uk>. Acesso em: 16 mar. 2012.

University applications from UK-born students fall 15\%. The Guardian, Londres, UK, 28 nov. 2011. Disponível em: <http://www.guardian.co.uk/education/2011/nov/28/ university-applications-uk-students-fees>. Acesso em: 16 mar. 2012.

Recebido em setembro de 2012 Aprovado em novembro de 2012 